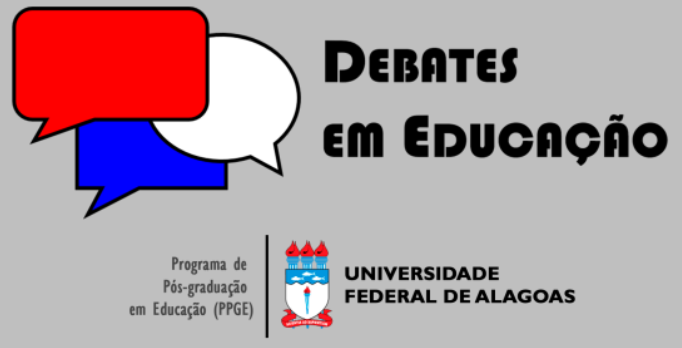

ISSN Eletrônico 2175-6600

Vol. 12 | No. 26 | Jan./Abr. | 2020

\title{
ENSINO DE CIÊNCIAS DELINEADO POR REPRESENTAÇÕES SOCIAIS
}

\section{RESUMO}

$\bigcirc$ presente estudo analisou as representações sociais dos sujeitos-alunos do Programa Nacional de Integração da Educação Profissional com a Educação Básica na Modalidade da Educação de Jovens e Adultos (PROEJA) no curso de artesanato sobre as infecções virais, e suas implicações na/para as práticas curriculares no ensino de Ciências. Trata-se de uma pesquisa de natureza qualitativa do tipo estudo de caso. $\bigcirc$ corpus de análise foi coletado por ocasião da realização da estratégia do grupo focal, e, para análise, procedemos à Análise Textual Discursiva (ATD). Os resultados apontam que as representações sociais dos alunos sobre o conteúdo que trata acerca das infecções virais desponta interesses e dúvidas em relação aos sintomas, tratamento, forma de contágio, diagnóstico, entre outros.

\section{Paula Roberta Galvão Simplício (9) iD \\ Universidade Federal de Alagoas (UFAL) paularoberta.gs@gmail.com}

\section{Adriana Cavalcanti dos Santos}

9 iD

Universidade Federal de Alagoas (UFAL) adricavalcanty@hotmail.com
Palavras-chave: Representações sociais. Ensino de Ciências. Artesanato no PROEJA.

\section{SCIENCE TEACHING DRAWN UP BY SOCIAL REPRESENTATIONS}

\section{ABSTRACT}

The present study analyzed the social representations of the student-subjects of the National Program for the Integration of Professional Education with Basic Education in the Modality of Youth and Adult Education (PROEJA) in the course of artisanship about viral infections, and its implications for curricular practices in science teaching. It is a qualitative research of case study type. The corpus of analysis was collected when the focus group strategy was carried out, and, for analysis, we proceeded to Discursive Textual Analysis (ATD). The results show that students' social representations about the content that deals with viral infections raise concerns and doubts regarding symptoms, treatment, form of contagion, diagnosis, among others.

Keywords: Social representations. Science teaching. Artisanship in PROEJA.

Submetido em: 08/08/2019

Aceito em: 17/12/2019

Publicado em: 06/04/2020

do: http://dx.doi.org/10.28998/2175-6600.2020v12n26p562-581 


\section{INICIANDO O DIÁLOGO}

A Teoria das Representações Sociais (TRS) traz uma abordagem plurimetodológica, abrangendo diferentes conceitos do cotidiano, sendo capaz de proporcionar uma ampla discussão se associada ao contexto escolar, especialmente, em relação aos saberes prévios dos alunos.

A Teoria das Representações Sociais (MOSCOVICl, 20 I5) pode ser potencializada em relação aos diferentes temas abordados no ensino de Ciências, e que traz significações epistemológicas, de acordo com as diferentes formas de conceber a aprendizagem pode ser uma aliada no processo educativo, formativo e emancipatório dos sujeitos.

Nesse sentido, o tema: infecções virais presente no componente curricular de Biologia, ao ser abordado em sala de aula, provoca significações singulares, e os sujeitos-alunos, ao serem convidados a socializarem os seus saberes, demostram e contam suas vivências cotidianas. Essas significações podem ser salientadas, em contexto, a fim de problematizar o entendimento que os alunos já apresentam sobre a temática, assim como fomentar o ensino e a aprendizagem, através da exposição das representações sociais pautadas no senso comum dos diferentes sujeitos.

Nessa perspectiva, os sujeitos do Programa Nacional de Integração da Educação Profissional com a Educação Básica na Modalidade da Educação de Jovens e Adultos (PROEJA), em sua maioria, apresentam uma trajetória de vida e escolar pautada em experiências, em relações cotidianas, na produção de sentido sobre o mundo e interpretações do real em sua estrutura cognitiva. Essa trajetória gera conhecimento epistêmico, e proporciona um corpus para investigação no âmbito escolar singular, que pode trazer reflexões para o meio acadêmico, assim como contribuições para repensar as práticas curriculares de ensino de Ciências no PROEJA.

Para iniciar a investigação, delineamos como problema de pesquisa: de que modo os sujeitosalunos do PROEJA expõem suas representações sociais sobre as infecções virais nas práticas curriculares de ensino de Ciências? Buscamos compreender as distintas maneiras que os estudantes buscam para interpretar situações cotidianas, especialmente, acerca das infecções virais e de que modo constroem o entendimento sobre os conhecimentos científicos por meio da associação entre o abstrato e o real, apresentando assim em sua estrutura cognitiva a formação do conhecimento, a partir dos sentidos que são dados ao que é material e o que é filosófico (JODELET, 1993).

O estudo teve como objetivo analisar as representações sociais dos sujeitos alunos do PROEJA sobre as infecções virais, no contexto das práticas curriculares de ensino de Ciências. Com caminhos metodológicos, pautados na abordagem qualitativa (LUDKE; ANDRÉ, 20।4), através da coleta de dados, a partir do grupo focal (GATTI, 20 I2), com o intuito de que suas representações sociais fossem expostas através da linguagem. 
Considerando que o PROEJA abrange uma ampla formação articulando modalidades de ensino Educação de Jovens e Adultos (EJA) e a Educação Profissional, a nível Médio - sendo constituído por sujeitos-alunos que despontam de vasta experiência acerca do mundo (BEZERRA; SANTOS, 20I6), possuem identidade e valores construídos a longos anos, constroem sentidos a partir do social, apresentam pensamentos divergentes e interpretações, algumas vezes, únicas, somos instigados a pesquisar e adentrar nesse mundo de pessoas que detêm representações sociais singulares em relação à diversidade de conteúdos que implicam as práticas curriculares.

O presente artigo está dividido em quatro seções. Na primeira ressaltam-se as representações sociais em diálogo com os modelos mentais. Na segunda, são tratados os dilemas e desafios na formação dos sujeitos do PROEJA e as diferentes compreensões sobre as infecções virais. Na terceira explica-se, de forma breve, a abordagem metodológica da pesquisa. A última traz os saberes dos sujeitos do PROEJA sobre infecções virais na perspectiva das representações sociais, finalizando com as considerações referentes a pesquisa.

\section{REPRESENTAÇÕES SOCIAIS EM DIÁLOGO COM OS MODELOS MENTAIS}

A TRS se caracteriza como uma abordagem teórico-metodológica que perfaz as mais variadas áreas. (SANTOS, 2013). No campo educativo, ela pode se tornar uma aliada na construção do conhecimento dos sujeitos, levando em consideração um viés participativo nas práticas curriculares, bem como na aprendizagem efetiva e reflexiva, consequentemente, mais inclusiva. Assim, Jodelet (I993, p. 4) afirma que:

[...] as representações sociais são fenômenos complexos sempre ativos e agindo na vida social. Em sua riqueza fenomênica assinalam-se elementos diversos, os quais são às vezes estudados de maneira isolada: elementos informativos, cognitivos, ideológicos, normativos, crenças, valores, atitudes, opiniões, imagens etc.. Mas esses elementos são sempre organizados como uma espécie de saber que diz alguma coisa sobre o estado da realidade.

Em face disso, as representações sociais são construídas, a partir da realidade em que os sujeitos atribuem sentidos para determinados fatos, conteúdos e objetos. Essa forma de ver o mundo pode ser compartilhada nas relações sociais, nos grupos em que o sujeito está inserido, sendo essas significações importantes para a construção do conhecimento científico na escola.

As representações sociais dos indivíduos podem ser vistas como uma visão funcional do mundo, que permitem dar sentido à sua conduta, entender a realidade e, através da atividade mental, reconstituir o real, além de trazer significações próprias (MAZZOTTI, 2002). Assim, referenciar as representações sociais dos diferentes sujeitos do PROEJA apresenta um viés didático-metodológico ancorado em 
conceituações específicas pautado em experiências próprias, que podem trazer significados para o processo de aprendizagem do aluno, como participante da sua formação.

Nesse sentido, as representações sociais podem contribuir para a compreensão acerca das distintas temáticas no ensino de Ciências desenvolvidas em sala de aula, em que desponta a possibilidade de associação do que é real e prático através da vivência dos sujeitos articulados com a teoria que perfaz o conhecimento científico, fomentando, nessa perspectiva, a potencialização dos processos de ensino e de aprendizagem mais significativos que colocam os sujeitos-alunos como autônomos e no centro do processo de formação o qual estão inseridos, desconstruindo o enquadramento curricular tradicional.

Nessa perspectiva, o estudo dos modelos mentais consente com a TRS, em que representações internas, ou representações mentais, são maneiras de representar e/ou apresentar internamente o mundo externo. As pessoas não captam o mundo exterior diretamente, elas constroem representações mentais, internas dele, de forma que essas informações correspondem analogamente com aquilo que está sendo representado. Johnson-Laird sugere que as pessoas raciocinam com modelos mentais. Modelos mentais são como blocos de construção cognitivos que podem ser combinados e recombinados conforme necessário (MOREIRA, 1996).

Destarte, podemos considerar essa articulação entre modelo mental e representação social uma contribuição para a (res)significação de saberes presentes na estrutura cognitiva do sujeito. A representação é, pois, segundo Jodelet (1993, p. 5) "a representante mental do objeto que reconstitui simbolicamente". (JODELET. Desse modo, as representações podem levantar uma nova perspectiva em relação à aprendizagem significativa e a produção de sentidos para os sujeitos do PROEJA.

Nessa perspectiva, entendemos com Freire (1996, p. 22) que [...] "ensinar não é transferir conhecimento, mas criar as possibilidades para a sua produção ou a sua construção". Assim, o aluno deve ser o construtor de sua autonomia e do seu conhecimento, sendo o professor mediador para essa construção da aprendizagem através dos saberes de senso comum dos sujeitos. Assim, a TRS constitui uma relevante abordagem estratégico-metodológica para ser utilizada em sala de aula, com o intuito de tornar os participantes atuantes e críticos em seu processo formativo e na interpretação dos conceitos em sua estrutura cognitiva.

Podemos ainda completar a construção do conhecimento, segundo Moscovici (2015, p. I5): "as representações não podem ser tomadas como algo dado nem podem elas servir simplesmente como variáveis explicativas". Dessa maneira, as representações sociais dos sujeitos são fruto de uma compreensão e interpretação de vida, proporcionando ao sujeito criar seu entendimento e concepções.

Além disso, a TRS aborda considerações singulares inerentes ao ser humano que pode ser transposta para a sala de aula, como algo que levanta contribuições para a explicação de fatos científicos ancorados no senso comum. 


\section{PROEJA: CONTEXTO E SUJEITOS}

A respeito dos discursos generalistas sobre o PROEJA, não devemos apenas levantar questões e significações que foram e são discutidas constantemente como: a falta de acesso ás escolas; falta de investimento; falta de cumprimento das diretrizes impostas. mas devemos direcionar o nosso foco de investigação também ao fazer pedagógico, às práticas curriculares, e sobre os valorosos saberes que estes sujeitos-alunos trazem para a escola. Esses saberes, significados em contextos reais, podem ser contributos para a ascensão e o sucesso no Programa.

É importante reiterarmos que, conforme Moura e Henrique (2012), um dos desafios é decorrente da falta de formação prévia dos professores para atuar com os alunos, além da falta de material didático específico para o PROEJA, implicando, assim, a utilização, muitas vezes, do material específico da EJA que desconsidera as especificidades e diversidades desses alunos, entre as quais: a faixa etária, os diversos níveis de maturidade intelectual, de experiência de vida e de domínio no uso dos recursos linguísticos. Conforme documento Base do PROEJA.

Os saberes produzidos são também reconhecidos e legitimados, e evidenciados por meio de biografias e trajetórias de vida dos sujeitos. Compreende-se que são eles decorrentes dos variados espaços sociais que a população vivencia no seu estar e ser no mundo, seja cultural, laboral, social, político e histórico (BRASIL, 2007, p. 42-43).

De tal forma que os saberes dos sujeitos, construídos em suas relações com o mundo, implicam a construção de um Currículo integrado à experiência dos alunos, entendendo assim que, os sujeitos-alunos do PROEJA possuem representações sociais sobre os temas abordados, e o currículo em construção na escola (YOUNG, 20I I), desmistificam o entendimento da condição de sujeitos que não podem aprender ou que o currículo de exclusão histórica dos referidos sujeitos à escola, deve ser adaptado com a finalidade de redução e/ou "simplificação" das temáticas abordadas em sala de aula.

Desconstruindo essa perspectiva, estamos a defender o postulado de que cada sujeito possui seu nível de maturidade e de conhecimento, demarcado por seus traços identitários. Reafirmamos a importância desses saberes, no âmbito da aprendizagem escolar, conhecimento poderoso (YONG, 20 I 0), num contexto em que o ensino de Ciências, em sua amplitude, corrobora com temas presentes no cotidiano dos alunos, possibilitando que suas representações sociais podem ser postas com maior ênfase e fundamento. 


\section{ABORDAGEM METODOLÓGICA}

A pesquisa configura um recorte da dissertação de Mestrado Profissional em Ensino de Ciências e Matemática, que investiga a interface entre ensino de Ciências e representações sociais dos sujeitos-alunos do PROEJA, em relação ao tema específico, infecções virais.

A investigação, com aprovação do comitê de ética sob $n^{\circ}$ 2.304.187, respeita assim os critérios éticos, conforme a resolução CNS n 466/12 e foi delineada a partir de uma abordagem qualitativa (LUDKE; ANDRÉ, 20।4), do tipo estudo de caso, baseada em Yin (2010, p. 39). que busca "entender um fenômeno da vida real em profundidade, mas esse entendimento engloba importantes condições contextuais".

A coleta de dados realizada através do grupo focal, com o auxílio de uma moderadora, nesta ocasião a pesquisadora, se sustenta em uma técnica de levantamento de dados que, segundo Gatti (2012, p. 9), "permite fazer emergir uma multiplicidade de pontos de vista e processos emocionais, pelo próprio contexto de interação criado, permitindo a captação de significados que, com outros meios, poderiam ser difíceis de se manifestar." As análises foram feitas à luz da Análise Textual Discursiva (ATD) (MORAES; GALIAZZI, 2013). Os discursos produzidos nos referidos grupos, representativos dos sentidos que os sujeitos atribuem ao conteúdo infecções virais na prática, no cotidiano, permitiram analisar suas representações sociais, e, a partir delas, foi possível apontar para o processo de reconstrução dos saberes sobre a referida temática no contexto escolar. (SANTOS; et. al, 20I5)

A investigação se deu em uma turma do $5^{\circ}$ período do PROEJA, do Instituto Federal de Alagoas (IFAL) no município de Maceió, no curso de artesanato. Participaram do referido grupo focal I 5 sujeitos, sendo I 4 mulheres e I homem. Na ocasião, cada sujeito pode contribuir para a construção discursiva sobre o tema abordado, demarcando suas identidades e particularidades na forma singular e coletiva, fomentando uma construção discursiva instigante.

Vale salientar que, antes de propormos o grupo focal, adentramos no contexto de sala de aula para observarmos a turma. Tal prática teve por intuito perceber as formas de interações na turma, além de tornar a investigadora familiar, e deixar os alunos confortáveis em relação à pesquisa. Por conseguinte, sensibilizamos a turma sobre a participação no grupo focal e a relevância da temática. Coletamos, ao longo da investigação, informações pessoais por meio de um questionário semiestruturado. A análise dos referidos questionários, possibilitou conhecer o perfil pessoal e profissional dos alunos. Essa etapa caracteriza-se como importante, devido ao fato de podermos conhecer um pouco sobre a trajetória escolar de cada sujeito. Vejamos o perfil da turma: 


\begin{tabular}{|c|c|c|}
\hline \multirow{2}{*}{ Quadro I - Perfil dos sujeitos investigados } \\
\cline { 2 - 3 } Aspectos abordados no Perfil & \multicolumn{2}{c|}{ Sistematização dos resultados } \\
\cline { 2 - 3 } & Homens & Mulheres \\
\hline Quantidade de alunos participantes & I aluno. & Entre 28 e 65 anos. \\
\hline Idade & 68 anos. & $\begin{array}{l}8 \text { casadas; } 3 \text { solteiras; } \\
\text { I divorciada; } 2 \text { viúvas. }\end{array}$ \\
\hline Estado Civil & Casado. & Entre 0 e 3 filhos. \\
\hline Quantidade de filhos 40 anos. \\
\hline Tempo de afastamento da escola & 2 filhos. & 7 trabalham; 7 não trabalham. \\
\hline Situação laboral & 50 anos. & Aposentado. \\
\hline
\end{tabular}

Fonte: Elaboração própria (2020).

Percebemos, através do levantamento do perfil da turma, as diferentes identidades e, sobretudo, a variedade de idades e tempo de afastamento da sala de aula, o que permite a esses sujeitos uma vasta concepção sobre o mundo (FREIRE, 1996). Essas concepções podem se configurar em um excelente ponto de partida para a discussão das diferentes temáticas que compreendem o currículo de Biologia.

Um outro aspecto refere-se à turma que é composta, em sua maioria, por mulheres, talvez atrelado ao fato de ser um curso voltado para o artesanato, em que o Plano de Curso de técnico em artesanato-Instituto Federal de Alagoas (IFAL, 2008) preconiza que "o Curso visa atender a profissionais atuantes na atividade artesanal com a proposta de revitalizar seus conhecimentos adquiridos tradicionalmente de geração para geração com fundamentação teórico-prático com foco no design". Isso faz com que sujeitos do sexo feminino sejam atraídos com mais facilidade para essa área. Entretanto, nada impede que os homens também tenham ascensão nesse mercado profissional, o qual possui uma infinidade de trabalhos manuais e criativos.

Por conseguinte, apresentamos o gráfico I, que demonstra as expectativas que os sujeitos do PROEJA almejam com a volta aos estudos, e, a volta aos estudos traz perspectivas as quais instigam esses sujeitos à continuidade do seu processo de escolarização.

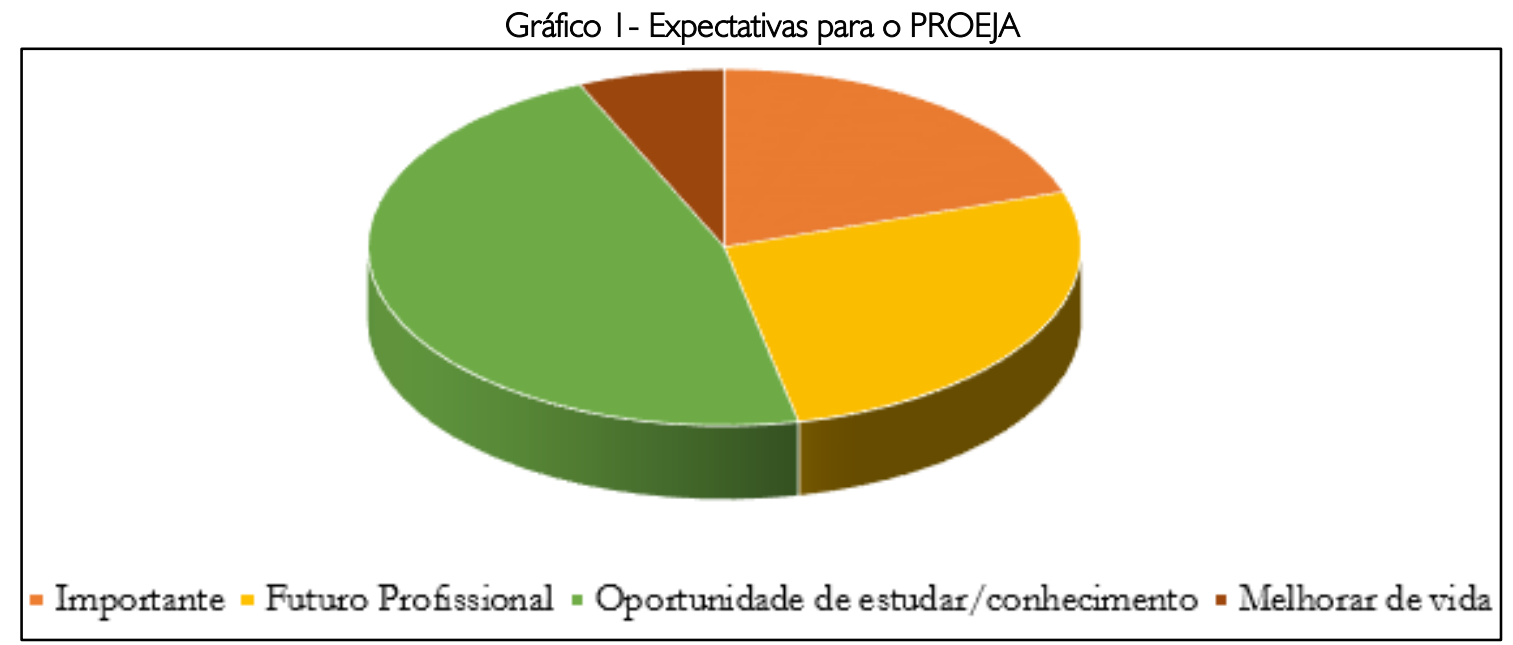

Fonte: Elaboração própria (2020). 
É importante salientar que os sujeitos do PROEJA comungam de pensamentos parecidos quando perguntados o que esperam dessa modalidade de ensino, mostraram o envolvimento na busca por um futuro melhor, através da obtenção de conhecimento e aperfeiçoamento de suas técnicas de trabalho, embora já tralhavam com formas de produção e comércio de artesanato.

Os discursos dos alunos, sistematizados no gráfico I, mostram que 47\% dos sujeitos veem no PROEJA a oportunidade de retomada aos estudos, enquanto que $27 \%$ dos alunos enxergam no PROEJA uma possibilidade para inserção no mercado de trabalho ou o aperfeiçoamento de suas técnicas artesanais. 20 \% explicitam que é importante, não deixando claro a qual importância faziam referência. No entanto, de algum modo esses alunos veem a volta aos estudos como algo singular, relevante para o seu processo de profissionalização. Apenas $7 \%$ generalizaram suas expectativas em relação ao PROEJA, ao responderem que pretendem melhorar suas condições de vida.

Em síntese, o perfil dos sujeitos investigados atrelados as suas expectativas para com suas aprendizagens e a melhoria de suas condições de vida, após a conclusão do curso, torna-se aliado do professor, à medida que as práticas curriculares são pensadas a partir das realidades dos sujeitos e dos seus saberes, estes provenientes de suas representações sociais.

Com o objetivo de analisar as representações sociais dos sujeitos-alunos do PROEJA sobre as infecções virais realizamos um grupo focal. Os discursos coletados no referido grupo, como mostraremos no diálogo com o corpus coletado, as concepções dos participantes do grupo sobre as infecções virais a expressam de múltiplos olhares sobre um tema, que, de certo modo, aproximam-se das prescrições do currículo escolar, e, como o referido tema ainda não havia sido abordado em sala de aula, possibilitou-nos a coleta de narrativas de contextos em que os sujeitos vivenciaram ou obtiveram informações sobre infecções virais, que geraram suas representações sociais.

\section{REPRESENTAÇÕES SOCIAIS: DESVELANDO SABERES SOBRE INFECÇÕES VIRAIS}

As representações sociais, entendidas como a atribuiç̧ão de sentidos aos objetos e fatos que os sujeitos-alunos do PROEJA possuem, provenientes de sua trajetória de vida, mostram-nos caminhos possíveis de abordagens de conteúdos no ensino de Ciências.

Nesse pensar, torna-se relevante fazer emergir as representações sociais desses alunos sobre temas que façam parte de seu cotidiano e contexto social, de tal forma que thes proporcione o entendimento do seu papel de participante ativo nos processos de ensino e de aprendizagem. É preciso considerar também a expressão da linguagem do sujeito e a participação através da exposição de sentidos que são criados em sua estrutura cognitiva para a formação do conhecimento, em que as representações 
sociais podem emergir em meio ao diálogo, em um grupo, escolar atribuindo significado as temáticas abordadas.

Os discursos se entrelaçaram em meio ao coletivo da turma do PROEJA, em que as narrativas sobre as infecções virais dos sujeitos-alunos foram tomando sentido e sendo construídas ao longo do grupo focal, através da mediação da moderadora do grupo, em consonância com a temática de diálogo proposta. Das narrativas, coletadas no referido grupo, emergiram conceitos que foram atribuídos a categorias de análise, a saber: vírus no cotidiano; tratamento das infecções virais; prevenção contra os mosquitos; microcefalia. Isso nos permitiu debruçar sobre questões de pesquisa, no entrelaçamento entre representações sociais e ensino de Ciências.

\section{I Representações sociais sobre Vírus no cotidiano}

As representações sociais são complexas e escritas em pensamentos preexistentes e dependem do sistema de crenças com aporte em valores, tradições e interpretações de mundo, com a incorporação de novos fenômenos, que permitem construir sistemas de pensamento e de compreensão, para adotar visões consensuais de ação que lhes permitem manter um vínculo social. Nesse sentido, representar significa trazer presentes as coisas ausentes e apresentar coisas de tal modo que possuam argumentos racionais integrados ao grupo de forma comunicativa e difusa (MOSCOVICl, 20 I5).

Nesse sentido, os sujeitos investigados apresentaram representações sociais distintas, pautadas em sua experiência de vida e crenças, de forma que apresentaram a construção e a interpretação de suas ideias sobre as infecções causadas por vírus, quando problematizamos: o que são vírus? No contexto do grupo focal, afirmaram:

Aluno I '- Vírus, é o vírus da gripe. Está com uma virose. Eu sei alguma coisa, porque minha mulher é enfermeira, e entende dessas coisas. Mas eu profundamente não sei.

Aluna 2- HIV é um vírus, a Aids.

Aluna 3- A tuberculose é um vírus ou uma bactéria?

Tais considerações apontam que os sujeitos-alunos mostram conceitos construídos coletivamente nas relações pessoais e sociais, e que essas representações podem estar presentes de forma enraizada devido a sua trajetória de vida e sua experiência. Os conceitos de Vírus elencados pelos alunos se compartimentam em relação à exposição de suas compreensões do cotidiano, de tal forma, que o aluno I demonstra que o conhecimento advém de uma pessoa próxima ou, muitas vezes, esses saberes passam de geração para geração, em que as explicações tradicionais apresentam-se muito fortes nesses sujeitos. Podemos conceituar vírus, conforme Actor (2014, p. 125): 
[...] os vírus são entidades pequenas (20-300nm) cujo genoma se replica no interior das células, utilizando a maquinaria celular do hospedeiro para gerar sua progênie de vírions (partículas virais). Por si só, um vírus pode ser considerado um complexo bioquímico inerte de macromoléculas, já que o mesmo não pode replicar no exterior de uma célula viva. Entretanto, os vírus são conhecidos por infectar todos os organismos vivos, e uma grande variedade de vírus contribui para as infecções em humanos.

Assim, os vírus são inertes fora de uma célula, por isso são considerados parasitas intracelulares obrigatórios, os quais só se reproduzem e têm metabolismo dentro de um hospedeiro. $\bigcirc$ ser humano pode ser contaminado por uma variedade de vírus que desenvolve diferentes doenças; dessa forma causam muitas dúvidas e incertezas nos alunos. Algumas dessas inquietações podem ser sanadas em sala de aula com a exposição dos pensamentos dos sujeitos de maneira a viabilizar a (res)significação de saberes.

Na fala da ALUNA 2, ela entende a relação entre o vírus causador da doença e a doença propriamente dita. Muitas vezes, os alunos confundem essa relação entre o agente causador e a infecção gerada. Segundo Levinson e Jawetz (2005, p. 299),

[...] o vírus da imunodeficiência humana (HIV) é a causa da síndrome da imunodeficiência adquirida (AIDS). O HIV-I e o HIV-2 causam AIDS, porém o HIV-I é encontrado no mundo inteiro, enquanto o HIV-2 é encontrado principalmente no África ocidental [...] O HIV infecta e destrói células T auxiliares, resultando em supressão da imunidade mediada por células. Isso predispõe o hospedeiro a diversidade a diversas infecções oportunistas e determinados tipos de câncer, como o sarcoma de Kaposi e os linfomas.

Destarte, o HIV é o vírus e a Síndrome da Imunodeficiência Adquirida (AIDS) é uma doença viral causada por ele, que se torna grave, devido ao fato de infectar células do sistema imunológico, deixando o corpo vulnerável a diferentes tipos de doenças. Esse conceito pode confundir os sujeitos-alunos, de modo que para o entendimento dessa temática se faz importante abordagens metodológicas diferenciadas, nas quais os alunos possam participar e interagir no processo de ensino e de aprendizagem, expondo as suas representações sociais sobre os temas abordados.

A ALUNA 3 apresenta uma dúvida, muito comum, da qual pode emergir conceitos equivocados acerca dos vírus, devido à troca de agentes patológicos causadores de doenças. Vale ressaltar que é comum os sujeitos apresentarem incertezas sobre o que é vírus e a doença que é causada pela contaminação viral, podendo esses conceitos serem reconstruídos no contexto escolar. Dessa forma, articular a realidade a conteúdos vistos na escola promove uma forma diferenciada na forma de aprender, que, segundo Chassot (2003, p. 3I), considera que "a nossa responsabilidade maior no ensinar Ciência é procurar que nossos alunos e alunas se transformem, com o ensino que fazemos, em homens e mulheres mais críticos."

Outra fala, representativa do grupo focal, foi a da ALUNA 2, que em meio as discussões, fez uma indagação e a responde ao mesmo tempo, enunciando: "Só quem pica são as fêmeas do mosquito é? Para se alimentar e para a reprodução, para maturar seus ovos". Ela mostra que dispõe de conhecimento sobre Ciências no que diz respeito à transmissão de doenças através do mosquito. Isso mostra seus saberes de senso comum, que advém de outros momentos de escolaridade e/ou de suas relações sociais, e essa 
informação as pessoas acabam passando de geração para geração, devendo ser em levadas para a escola, com o intuito de ampliar a significação desses conceitos.

Diante de tal concepção, é necessário lembrar Jodelet (1993, p. I) que afirma: "sempre necessitamos saber o que temos a ver com o mundo que nos cerca. É necessário ajustar-se, conduzir-se, localizar-se física ou intelectualmente, identificar e resolver problemas que ele põe. Eis porquê construímos representações". Ainda nesse sentido é importante reiterar que buscamos interpretações para o que está a nossa volta, de forma que esses conceitos, se colocados no contexto da escola, trazem uma significação para os alunos. Segundo Cordeiro (2008, p. 20),

[...] a temperatura pode também afetar a maturação dos mosquitos; altas temperaturas produzem fêmeas menores que são forçadas a se alimentar um maior número de vezes a fim de ingerir o volume de sangue necessário para obter a proteína para a maturação dos ovos. Isto tem efeito no aumento do número de indivíduos infectados por uma única fêmea e também na capacidade vetorial do mosquito.

Nesse sentido, em diálogo com a ALUNA 2, as fêmeas dos mosquitos também são hematófagas, ou seja, se alimentam de sague para a produção e desenvolvimento dos ovos. A aluna apresenta sua interpretação de um assunto que ainda será abordado em sala de aula, em que a discussão partindo dos saberes prévios, traz uma perspectiva didática que pode colocar estes como fundamentais no processo de tessitura de seu conhecimento e na construção de uma aprendizagem significativa.

\subsection{Representações sociais sobre as infecções virais}

A turma apresentou muita curiosidade sobre o tema tratado, pois além de demonstrar seus conhecimentos empíricos e dúvidas, socializaram relatos de experiência acerca de doenças acometidas pelos seus corpos.

A partir dessas experiências, emergiram falas que descreveram as doenças com as quais esses sujeitos entraram em contato em algum momento de suas vidas. Dentre as falas, tomamos como representativa a da ALUNA 4, ao proferir: "Eu tive Zika. Mas nem tive sintomas antes. Estava na igreja, e quando olhei estava cheia de manchas vermelhas pelo corpo. Achei estranho, porque minha pele não era assim. Depois tive um pouco de febre, porém os sintomas foram fracos". A aluna evidenciou assim seu conhecimento sobre os sintomas da infecção que teve e mostrou que seus saberes estavam pautados na experiência que obteve, entrando em contato com o vírus, de tal forma que foram formadas representações da infecção que obteve. Desse modo, tais representações podem potencializar, de modo a tornar o sujeito crítico, consciente da construção da sua aprendizagem no âmbito escolar.

Em face disso, podemos entender que o vírus é transmitido pelo mosquito Aedes aegypti, em que os sintomas aparecem repentinamente. De acordo com Levinson e Jawetz (2005, p. 280), 
[...] não existe vacina ou terapia antiviral. Surtos podem ser evitados pelo uso de inseticidas e pela drenagem das águas estagnadas que servem de local de reprodução para os mosquitos. Para a proteção pessoal, é aconselhado o uso de repelentes para mosquitos e de roupas que cubram todo o corpo.

Nesse sentido, salientar temas como esse no ambiente escolar pode proporcionar a retirada de dúvidas, a exposição de relatos de experiência, os quais podem ser associados ao conhecimento científico, e potencializar um processo de aprendizagem mais significativo ${ }^{1}$ e inclusivo para todos. Nesse tocante, o trecho apresenta formas de prevenção para os sujeitos, que, muitas vezes, não são levados em consideração em seu cotidiano, e, a partir de sua aprendizagem, os alunos podem ser multiplicadores de conhecimentos e ações.

Percebemos que os alunos, no contexto do grupo focal, expuseram o que já passaram ou sentiram em relação ao tema da construção discursiva do referido grupo. Dessa forma, se os sujeitos possuírem espaço no ambiente escolar para representar seus pensamentos, esses poderiam ser usados pelo professor como ponto de partida para iniciar o diálogo sobre os diversos temas apresentados pelo currículo escolar. Segundo Freire(1996, pp. 30-3 I), as indagações sobre a realidade precisam ser trazidas para o centro do processo educativo.

Por que não discutir com os alunos a realidade concreta a que se deva associar a disciplina cujo conteúdo se ensina, a realidade agressiva em que a violência é a constante e a convivência das pessoas é muito maior com a morte do que com a vida? Por que não estabelecer uma 'intimidade' entre os saberes curriculares fundamentais aos alunos e a experiência social que eles têm como indivíduos? Por que não discutir as implicações políticas e ideológicas de um tal descaso dos dominantes pelas áreas pobres da cidade? A ética de classe embutida neste descaso? Porque, dirá um educador reacionariamente pragmático, a escola não tem nada a ver com isso. A escola não é partido. Ela tem que ensinar os conteúdos, transferi-los aos alunos. Aprendidos, estes operam por si mesmos.

Elucidar a realidade dos sujeitos-alunos e a oportunidade de exposição de suas opiniões pode trazer um novo viés para suas aprendizagens, em que podem discutir sobre uma variedade de conteúdos em sala de aula, desmistificando assim, a visão de sujeitos adultos que não conseguem desenvolver uma aprendizagem significativa.

Outra fala que nos chamou a atenção foi a do ALUNO I, pois ele apresentou um discurso bastante conciso a respeito da gripe, ao enunciar: "temos que esperar o ciclo da gripe. Ela tem um tempo de permanecia no corpo. Depois ela vai embora por si mesma. Mas temos que tomar vitamina $C$, remédio para baixar a febre, remédios para diminuir as dores. Mas não para combater a doença." (sic). Os saberes que o aluno revela no referido enunciado não advieram do PROEJA, devido ao fato de que os alunos ainda não tinham estudado sobre vírus, mas de seus saberes da experiência. $\bigcirc$ sentido produzido no enunciado do referido aluno mantém relação com o postulado de Levinson; Jawetz (2005, p. 247):

\footnotetext{
' Entendemos por aprendizagem significativa a construção de interpretações sobre determinado conteúdo na estrutura cognitiva do sujeito que seja de fato compreendida a fim de ser utilizada em outras situações e/ou torne o sujeito crítico capaz de opinar e refletir acercar de diferentes temáticas.
} 
[...] depois de um período de incubação de 24 a 48 horas, sintomas como febre, mialgia, cefaleia e tosse aparecem repentinamente. Mialgias severas (dores musculares) acompanhadas de sintomas do trato respiratório são típicas de influenza. Vômitos e diarreia são raros. Os sintomas normalmente desaparecem espontaneamente depois de 4 a 7 dias.

Nesse contexto, podemos entender os saberes do ALUNO I como singulares, mediante a sua explicação baseada na sua experiência de vida, que mantém relação com a literatura, o que podemos entender como conhecimento científico. Nessa ocasião, o aluno demonstra um relato sobre a gripe que é uma doença viral e que conforme citado acima, os seus sintomas desaparecem espontaneamente, de forma que é muito comum a infecção pelo vírus da gripe, pois a vacina é preventiva, mas não tem uma longa duração no corpo humano.

Vale ressaltar ainda que o aluno do PROEJA tece sentidos para entender aquilo que está a sua volta, de tal forma que as suas interpretações são formadas em sua estrutura cognitiva, e assim suas interpretações se aproximam do concreto sem possuir um conhecimento científico prévio, mas a partir de suas relações sociais apresentam conceitos que são representados socialmente. Como afirma Jodelet (1993, p.8):

As representaç̃es sociais devem ser estudadas articulando elementos afetivos, mentais e sociais e integrando, ao lado da cognição, da linguagem e da comunicação, a consideração das relações sociais que afetam as representações e a realidade material, social e ideal sobre a qual elas intervêm.

A produção de representação e a atribuição de sentidos pelos sujeitos, como demonstram os discursos apresentados, são formadas coletivamente no convívio dos sujeitos em seu meio social, no contexto em que esses entendimentos são passados entre sujeitos pertencentes ao mesmo grupo e/ou grupos diferentes. Compartimentar seus saberes, que demarcam seus traços de identidade, evidenciando elementos afetivos e sociais pode assumir um novo olhar para as práticas curriculares. Assim, pudemos evidenciar, nos discursos produzidos no grupo focal, que a participação dos alunos se torna singular na perspectiva de uma (re)contextualização de saberes (SANTOS, 20 I7).

\subsection{Representações sociais: prevenção contra os mosquitos}

Os discursos dos sujeitos participantes do grupo focal revelam as suas representações sociais sobre as formas de prevenção e contaminação do mosquito Aedes aegypti transmissor da Dengue, Chikungunya, Febre Amarela e o Zika vírus. Essas representações são expostas no meio social. Para Santos (20 I3, p. 12), "no processo de interação social o sujeito elabora o conhecimento, vai se socializando e (re) construindo valores e ideias que circulam na sociedade de modo bastante amplo".

Nesse sentido, o processo interacional possibilita o crescimento mútuo e singular para a vida do sujeito e para a sua aprendizagem na escola. Como já dito ao longo do texto, as representações sociais 
são construídas a partir das interações, da linguagem e da comunicação, de tal forma que a exposição dessas representações pode refletir de maneira significativa no âmbito escolar, proporcionando a (res) significação de saberes e reconfiguração do currículo (SANTOS; et. al, 20। 5)

Em diálogo no grupo focal, no contexto em que abordávamos concepções sobre a prevenção contra os mosquitos causadores de doenças, a ALUNA 5 explica as medidas preventivas utilizadas por ela para medida de proteção contra os mosquitos. Ela relata: "eu uso em casa mosquiteiro, repelente, cuido do lixo, não deixo água parada, mas o problema são os vizinhos. Moro perto de um córrego, onde tem bastante mosquito. Eu cuido do lixo, mas as pessoas não! Assim fica difícil." (ALUNA 5). Com essas considerações, a aluna mostrou-se preocupada com a preservação do ambiente e, principalmente, com a sua saúde, da sua família e da população ao seu entorno. Nos assuntos como esses, que tratam de temas referentes à saúde pública, devem ser ressaltado todos os cuidados, tratamento e medidas socioeducativas, visando a que os alunos sejam multiplicadores de ações e conhecimentos, uma vez que, cada vez mais assuntos como esses são tratados na mídia, e, mesmo assim, as pessoas não apresentam a devida conscientização.

Ainda nesse contexto, a aluna 6 exemplificou um fato ocorrido com ela, ao narrar: "eu também cuido do lixo, mas às vezes, os vizinhos jogam seus lixos até na minha porta. Como exemplo: essa semana, a vizinha passou e deixou o lixo na minha porta. Eu saí de casa e, educadamente, devolvi a ela" (ALUNA 6). A narrativa dessa aluna, mostra-nos a falta de conscientização e, especialmente, a falta de educação da população que não pratica as medidas necessárias, como nesse caso, para diminuir a proliferação de mosquitos, podendo, através desse ato, ocasionar sérios problemas de saúde para a população.

Nessa perspectiva, os alunos possuem saberes da experiência em sua estrutura cognitiva, que são expostos através de suas representações, acerca do mundo em que vivem. Neste sentido, conforme Santos (20 13, p. 12), "entende-se Representação Social como uma teoria ou ciência coletiva destinada à interpretação e á intervenção no real, indo além do que é imediatamente dado na filosofia e na sociologia acerca da classificação de eventos e fatos sociais". Assim, as falas dos sujeitos elencadas acima demonstram suas representações sociais, que Ihes permitem fazer interpretação dos fatos e, consequentemente, intervenção no que é real, permitem aos alunos o surgimento de um pensamento mais crítico e reflexivo, para que o aluno seja atuante na exposição de seus pensamentos em sala de aula, agregando assim positivamente na sua aprendizagem, bem como a da turma em âmbito geral.

Chamou nossa atenção a fala da ALUNA 4, em relação ao acúmulo de lixo e a proliferação de doenças.

Onde eu moro também acontece esse fato de jogarem o lixo em lugares incorretos. Um dia, eu precisei ir à casa da minha vizinha, que tinha um terreno. Ela jogava o lixo lá mesmo, não esperava o dia da coleta. Fui reclamar, e ela tentou resistir. Mas falei que chamaria a defesa civil. Pois se ela só tivesse fazendo mal para ela era bom. Mas estava fazendo mal para uma população acumulando lixo (ALUNA 4). (sic). 
Como se observa na narrativa, a aluna possui conhecimento de senso comum, em que podem ser abordados em sala de aula, de maneira que a aluna participe dos processos de ensino e de aprendizagem e as suas representações sociais podem colaborar para a intervenção socioeducativa em seu entorno, seja na escola ou em sua residência, levando em consideração que uma pequena ação, ou a multiplicação de ideias dentro de um grupo pode gerar resultados satisfatórios para todos os sujeitos próximos.

Diante das falas, percebemos que os alunos apresentam diversos saberes e a utilização da Teoria das Representações Sociais (TRS) na sala de aula pode trazer novas perspectivas para os alunos do PROEJA. Dessa forma, elucidar os saberes dos alunos sobre temas do cotidiano, em especial, que são abordados no ensino de Ciências, colocam os sujeitos como participantes do processo educativo, em que suas narrativas sobre a prevenção da proliferação dos mosquitos demonstram os seus saberes construídos na interação com o meio e que pode ser ponto de partida para novas aprendizagens.

\subsection{Representações sociais sobre Microcefalia}

Buscamos ressaltar, em contexto de grupo focal, os saberes dos sujeitos a respeito da microcefalia, considerando ser um tema que vem sendo bastante discutido na atualidade, devido aos novos casos que surgiram e, consequentemente, causam dúvidas sobre sua associação com o Zika vírus.

Levando em consideração que o ensino de Ciências, na área de Biologia, traz temáticas que instigam os alunos a pesquisarem e construir conhecimento sobre os mais variados temas, pois se caracterizam como temas do cotidiano dos sujeitos-alunos. Nesse contexto, faz-se importante a autonomia dos sujeitos no âmbito escolar, visto que, muitas vezes, são temas de seu entendimento, em que a participação na conceituação de assuntos diversos é essencial. É importante enfatizar que, muitas vezes, não se nota preocupação com aspectos importantes, como as relações que dinamizam o conhecimento, os métodos e os valores das ciências biológicas, de forma que são cobrados conhecimentos factuais, em sua maioria, irrelevantes e desconexos, em relação às outras áreas da disciplina Ciências e às demais disciplinas do Currículo (KRASILCHIK, 2008).

Quando indagamos aos alunos o que eles sabiam sobre a microcefalia, as respostas foram as mais diversas. Em meio aos discursos surgiram dúvidas que mostraram o interesse acerca do tema, bem como ficou perceptível o quanto o levantamento de seus saberes pode repercutir em um diálogo que leva ao surgimento de representações dos alunos e na retirada de dúvidas contribuindo para a aprendizagem dos conhecimentos científicos.

A primeira fala se deu através da incerteza da ALUNA 7. Ela se propôs a perguntar: "é a cabeça grande e o cérebro pequeno?" Prontamente a ALUNA 2 Ihe respondeu: "é. Eu acho que tem a cabeça 
grande e o cérebro pequeno, ou não? Acho que é a hidrocefalia que a cabeça é grande, possuindo água no cérebro". Percebemos que a aluna se confunde e rapidamente faz uma correção em sua fala, de modo que os outros alunos aprendem de uma maneira diferenciada em que o professor não é apenas o centro da atenção, mas possibilita a interação entre os alunos podendo facilitar e potencializar o processo de ensino e de aprendizagem.

Podemos entender a diversidade de pensamento dos sujeitos de tal forma que o professor precisa proporcionar a articulação com os diferentes relatos dos alunos, dessa maneira não existindo uma forma concreta de se ensinar e aprender.

Segundo Pozo e Crespo (2009, p. 245),

[...] não existem "boas" ou "más" formas de ensinar, senão formas adequadas ou não para determinadas metas e em certas condições dadas e que, portanto, cada professor - ou cada leitor - deve assumir a responsabilidade do enfoque educacional que for mais adequado à sua concepção do aprendizado da ciência.

Nesse contexto, não existe uma técnica correta para se fazer ciência, para aprender ciência, até porque existem diferentes formas de aprendizado, diferentes tempos para que se dê a construção do conhecimento, ou seja, cada aluno tem uma forma diferenciada de aprender. Assim, deixar emergir as representações sociais com a participação do aluno do PROEJA como sujeito ativo no seu processo formativo, pode contemplar uma maior quantidade de sujeitos que construam uma aprendizagem significativa e que estejam instigados a estarem na escola e consequentemente diminuindo a evasão escolar. Ainda no que concerne á fala da ALUNA 2, segundo Sousa et. al, (2012, p. 55),

[...] o termo hidrocefalia vem do grego e significa 'água na cabeça'. Caracteriza-se por um aumento da quantidade e da pressão do líquor ou líquido cefaloraquidiano, levando a uma dilatação dos ventrículos e à compressão do tecido nervoso. A hidrocefalia não é uma doença específica. Antes representa um grupo diverso de distúrbios, os quais resultam do comprometimento da circulação e absorção do líquido cefaloraquidiano ou, em circunstâncias raras, produção aumentada por um papiloma do plexo coróide.

Compreendemos a tessitura de saberes, a partir da voz da aluna que apresenta um tema diferenciado do que estamos trabalhando e expande o viés do conhecimento, deixando mais clara a variedade de saberes apresentados pelos alunos, que demonstram a capacidade em aprender e ensinar dos sujeitos do PROEJA, em que o trecho traz o conceito de hidrocefalia que se equipara com o da aluna, com uma temática diferenciada, em que a hidrocefalia se caracteriza como água na cabeça, aumentando assim de tamanho.

Outra fala representativa é a da ALUNA 9 que se posicionou acerca da temática explicitando a respeito da microcefalia e suas implicações para a vida da criança:

[...] sobre a microcefalia, depende da área que foi atingida. A diferença é na circunferência da cabeça. Se atingir muito a massa encefálica, pode afetar mais, como: a visão e a audição. Vai depender do período que a mãe esteve em contato com o vírus. Sendo relativo de uma criança 
para outra, em que pode ter o raciocínio mais lento, afetar nas questões motoras (ALUNA 9). (Sic)

O excerto revela que a aluna dispõe de saberes decorrentes da sua vivência, e, quando indagada sobre como apresentava aquele conhecimento, a mesma explicou que: "através da mídia (TV, redes sociais). Eu queria me informar, porque eu tinha duas irmãs grávidas, e morava perto de uma maternidade. Então tinha bastante curiosidade, mas nunca vi uma criança com microcefalia". Entendemos, o interesse da estudante em ir em busca da informação para assim se prevenir e informar a sua família, sendo esse conhecimento válido em todos os âmbitos, inclusive em seu processo formativo pessoal e educacional.

Podemos ainda, verificar a pertinência de sua fala com os autores Rodrigues, Bouças e Errante (2016, p. 43) que trazem embasamentos científicos sobre a microcefalia.

A microcefalia corresponde a uma malformação congênita e o recém-nascido já nasce com perímetro cefálico igual ou menor que $33 \mathrm{~cm}$, avaliado por ultrassonografia após o nascimento. Em 90\% dos casos de microcefalia existe associação com retardo mental, exceto na microcefalia de origem familiar, onde pode ocorrer um desenvolvimento cognitivo normal.

Nesse contexto, as causas da microcefalia podem ser diversas. Ultimamente, foi associada ao contágio com o Zika vírus. Devido á ocorrência de casos recentes, os estudos vêm sendo constantes e pouco se sabe em relação ao desenvolvimento da criança, porém pode haver sequelas as quais podem ser diagnosticadas por exames e com o passar do tempo, para ter um diagnóstico preciso. Assim, a aluna já possui essa percepção através de seus conhecimentos pautados na busca por informações para sanar dúvidas e suas curiosidades, os quais são bastante pertinentes ao meio escolar. Conforme Gilly (2002, p. 233):

[...] o campo educativo aparece como um campo privilegiado para ver como se constroem, evoluem e se transformam as representações sociais no seio de grupos sociais, e nos esclarecer sobre o papel dessas construções nas relações desses grupos com o objeto de sua representação.

Em face disso, cabe ressaltar a importância da exposição das representações sociais no espaço educativo, sendo respaldado no PROEJA pela atuação dos sujeitos junto a seus saberes prévios, em que apresentamos o seu contexto prático nas distintas falas dos sujeitos-alunos. Vale ressaltar que os alunos do PROEJA possuem trajetórias que precisam ser pontuadas em sala de aula, pois suas representações (re)constroem sentido para sua permanência e avanço na escola.

\section{CONSIDERAÇÕES}

A sala de aula do PROEJA pode se tornar um ambiente muito atrativo, interativo e de singulares acontecimentos, em que os alunos podem ser autores de suas próprias histórias, e construir suas 
aprendizagens através de interpretações do mundo que os cerca. A postura do professor mediante os saberes dos alunos deve conduzi-los á percepção de que devem ser atuantes.

No mesmo sentido, a Teoria das Representações Sociais (TRS) configura uma abordagem teóricometodológica de significância para ser utilizada em investigações no âmbito escolar, podendo elencar interpretações particulares de cada turma e sujeito, levando em consideração que os alunos do PROEJA possuem longas trajetórias de vida, principalmente, fora da sala de aula. Isso não diminui a sua capacidade de aprendizagem, mas a enaltece devido as suas diferentes formas de conceber a aprendizagem, bem como os diferentes saberes.

Em especial, a turma do $5^{\circ}$ período do PROEJA, em que foi realizada a pesquisa, trouxe contribuições únicas para o desenvolvimento do grupo focal. No contexto em que foi perceptível que as representações sociais dos sujeitos podem e devem ser consideradas no contexto escolar, proporcionando a participação dos diferentes sujeitos, os quais precisam interagir na sociedade e na sala de aula, como críticos e reflexivos sobre diferentes assuntos cotidianos.

Esses sujeitos apresentaram inquietações sobre o tema infecções virais, pois seus relatos de experiência estão pautados em sua vivência com a doença, com os sintomas e com as formas de tratamento, abrangendo, assim, saberes que podem ser levados para além da escola. Em razão dessa realidade, percebemos a relevância da participação dos sujeitos-alunos em seu processo educativo por meio de suas representações sociais, que expressam saberes acerca do mundo em que vivem, podendo trazer implicações para uma aprendizagem que seja significativa para os sujeitos, bem como possibilitar uma flexibilidade do currículo no ensino de Biologia, através da atuação do sujeito nas aulas e fora dela.

A temática Infecções Virais, problematizada em contexto de grupo focal, vislumbra uma diferente perspectiva para o processo de ensino e de aprendizagem, bem como para o conhecimento e a potencialização do entendimento de conteúdos pelos alunos para que esses possam desenvolver uma aprendizagem de fato significativa, através de imagens interpretativas em sua estrutura cognitiva, representações sociais, trazendo assim distintos olhares para o ensino de Ciências.

\section{REFERÊNCIAS}

ACTOR, Jeffery K. Imunologia e Microbiologia. Trad. Irene T. Araújo e outros Rio de Janeiro: Elsevier, 2007.

ALAGOAS. Instituto Federal de Educação, Ciências e Tecnologia de Alagoas. Plano do Curso Técnico de Artesanato. Maceió, 2008.

BEZERRA, Danielle Barbosa; SANTOS, Adriana Cavalcanti. Ensino de ciências na educação de jovens e adultos: (res) significando saberes na produção de fanzines. Revista de Educação, Ciências e Matemática v.6 n. I jan/abr 2016. 
BRASIL. Programa Nacional Ensino Médio Integrado a Educação Profissional Técnica de Nível Médio na Modalidade do PROEJA: Documento Base. Brasília, 2007. Disponível em:

http://portal.mec.gov.br/setec/arquivos/pdf2/proeja medio.pdf. Acesso em : I 5 dez. 2017.

CHASSOT, Attico. Alfabetização científica: questões e desafios para a educação. 3.ed. - ljuí: Editora da Unijuí, 2003.

CORDEIRO, Marli Tenório. et. al. Vinte anos de evolução da dengue no Estado de Pernambuco. Ed. Universitária da UFPE, 2008.

FREIRE, Paulo. Pedagogia da autonomia: saberes necessários à prática educativa. São Paulo: Paz e Terra, 1996.

GATTI, Bernadete Angelina. Grupo focal na pesquisa em ciências sociais e humanas. - Brasília: Liber Livro Editora, 2012.

GILLY, Michel. As representações sociais no campo educativo. Tradução: Serlei Maria Fischer Ranzi; Maclóvia Correa da Silva. Revista educar, Curitiba, n. 19, p. 231-252. 2002.

JODELET, D. Représentations sociales: un domaine en expansion. In D. Jodelet (Ed.) Les représentations sociales. Paris: PUF, 1989, pp. 31-6I. Tradução: Tarso Bonilha Mazzotti. Revisão Técnica: Alda Judith Alves Mazzotti. UFRJ- Faculdade de Educação, dez. 1993.

KRASILCHIK, Myriam. Prática de ensino de biologia. - 4. ed. e ampl rev. - São Paulo: editora da Universidade de São Paulo, 2008.

LUDKE, Menga; ANDRÉ, Marli E.D.A. Pesquisa em educação: abordagens qualitativas.

2.ed. - reimpr. - Rio de Janeiro: E.P.U, 2014.

LEVINSON, Warren; JAWETZ, Ernest. Microbiologia médica e imunologia. Trad. José Procópio M. Senna. 7.ed. -Porto Alegre: Artmed, 2005.

MAZZOTTI, Alda Judith Alves. A abordagem estrutural das representações sociais. Psicologia da Educação, São Paulo, 14/15, $1^{\circ}$ e $2^{\circ}$ semestre, 2002, p. 17-37.

MORAES, Roque; GALIAZZI, Maria do Carmo. Análise textual discursiva. - 4.ed.- rev. reimpr.- ljuí: Editora da Unijuí, 2013.

MOREIRA, Marco Antonio. Modelos Mentais. Investigações em Ensino de Ciências - VI (3), pp. I93232, 1996.

MOREIRA, Marco Antonio. O Que é Afinal Aprendizagem Significativa? Mato Grosso, Cuiabá, Qurriculum, La Laguna, Espanha, 2012, v. I, p. I-27, 2012.

MOSCOVICl, Serge. Representações sociais: investigações em psicologia social. Editado em inglês por Gerard Duveen; traduzido em inglês por Pedrinho A. Guareschi. II. Ed.- Petrópolis, RJ: Vozes, 2015.

MOURA, D.H; HENRIQUE. A.L.S. PROEJA: entre desafios e possibilidades. Revista HOLOS, Ano 28, Vol 2, 2012. 
POZO, Juan Ignácio; CRESPO, Miguel Angel Gomez. A aprendizagem e o ensino de ciências: do conhecimento cotidiano ao conhecimento científico. - 5.ed. - Porto Alegre: Artmed, 2009.

RODRIGUES, Francisco Sandro Meneses; BOUÇAS, Rodrigo Ippólito; ERRANTE, Paolo Ruggero. Aspectos clínicos, epidemiológicos e correlação de microcefalia congênita pela infecção pelo vírus zika no Brasil. Science in Health; 7(I), 2016, p. 38-49.

SANTOS, Adriana Cavalcanti; et. al. Narrativas de alfabetização dos sujeitos da educação de jovens e adultos: os múltiplos sentidos dos/nos processos educativos. In: VIII Seminário Internacional As Redes Educativas e as Tecnologias: Movimentos Sociais e Educação. Junho/20 I5, Rio de Janeiro, 20 I 5.

SANTOS, Marcos Pereira. A teoria das representações sociais como referencial didático-metodológico de pesquisa no campo das ciências humanas e sociais aplicadas. Revista Emancipação, Ponta Grossa, I3(I), 20|3. p. 9-2I.

SANTOS, G. S. Política Curricular e recontextualização na escola: lições a partir da Rede Municipal de Ensino de Porto Alegre. Jornal de Políticas Educacionais. V. I I, n. 20. Dezembro de 2017.

SOUSA, et al. Hidrocefalia: revisão de literatura. Revista Universo; Vol 4, Número 6 Jornada Científica da UNIVERSO - Suplemento Saúde - Brasil, 20I2,

YIN, Robert K. Estudo de caso: planejamento e métodos. Tradução Ana Thorell- 4. Ed.- Porto Alegre: Bookman, 2010.

YOUNG, Michael F. D. Conhecimento e currículo: do socioconstrutivismo ao realismo social na sociologia da educação. Porto: Porto editora, 2010.

YOUNG, Michael F. D. O futuro da educação em uma sociedade do conhecimento: o argumento radical em defesa de um currículo centrado em disciplinas. Revista Brasileira de Educação, v. 16 n. 48, set./dez. 201 I. 